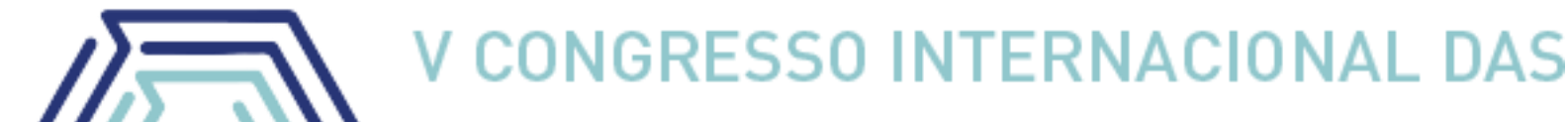 LICENCIATURAS COINTER - PDVL 2018
}

\section{REFORMA DO ENSINO MÉDIO: CONTEXTO, CARACTERIZAÇÃO E CONTRASSENSOS}

\section{REFORM OF MIDDLE SCHOOL: CONTEXT, DESCRIPTION AND CONTRASTS}

\author{
Apresentação: Pôster
}

Samuel do Nascimento Cândido Luz ${ }^{1}$; Luiz Brito de Souza Filho ${ }^{2}$; Ariane Craveiro Lima $^{3}$; Benedita de Oliveira Fernandes ${ }^{4}$; Karlane Holanda Araújo ${ }^{5}$

DOI: https://doi.org/10.31692/2358-9728.VCOINTERPDVL.2018.00239

\section{Introdução}

O presente artigo visa apresentar o contexto histórico originário do Novo Modelo do Ensino Médio e a caracterização da reforma, bem como analisar suas possíveis consequências nos sistemas de ensino, objetivando refletir a respeito da política educacional representada pela Lei Federal de no 13415 de 2017 que veio instaurar modificações na estrutura do sistema atual de ensino médio brasileiro. A elaboração desse escrito ocorreu a partir das discussões, das leituras e dos estudos coletivos realizadas nas aulas de Política Educacional, do curso de Licenciatura em química, do Instituto Federal de Educação, Ciência e Tecnologia do Ceará (IFCE - Campus Ubajara).

Com base nas pesquisas bibliográficas, refletimos acerca das influências políticas e econômicas na criação da Lei, assim como também abordamos algumas justificativas que levaram a aprovação da mesma e as mudanças que os sistemas de ensino deverão sofrer, apontando os principais aspectos que vão contra a efetivação da reforma e outros que sinalizam a necessidade da remodelação do ensino. A leitura do artigo poderá proporcionar um maior esclarecimento aos professores acerca do novo ensino médio e suas implicações no sistema educacional brasileiro, especialmente no cotidiano escolar.

\footnotetext{
${ }^{1}$ Química, Instituto Federal do Ceará, samueldonasci@gmail.com

${ }^{2}$ Química, Instituto Federal do Piauí, luiz.brito@ifpi.edu.br

${ }^{3}$ Química, Instituto Federal do Ceará, craveiroariane@gmail.com

${ }^{4}$ Química, Instituto Federal do Ceará, beneditaoliveira94@gmail.com

${ }^{5}$ Doutoranda, Universidade Federal do Ceará e Instituto Federal do Ceará, karlane.araujo@ifce.edu.br
} 


\section{Fundamentação Teórica}

O cenário brasileiro vive um momento atípico com um clima de reformas em vários setores, sendo um deles no âmbito da educação. Aprovada pela Lei Federal de no 13415 de 2017, a reforma do ensino médio veio instaurar modificações na estrutura do ensino secundarista no Brasil.

De acordo com os argumentos apresentados pelo Ministro de Estado da Educação José Mendonça Bezerra Filho, titular na época da aprovação da referida legislação, a proposta de um novo modelo de ensino médio surgiu devido aos baixos índices de desempenho dos estudantes em Língua Portuguesa e Matemática, conforme o Índice de Desenvolvimento da Educação Básica (IDEB) que não alcança as metas projetadas desde o ano de 2011; a existência de uma estrutura curricular com trajetória única para o conjunto de estudantes, cuja carga compreende 13 disciplinas, considerada excessiva e desvinculada com a realidade do aluno, sendo grande responsável pelo desinteresse e fraco desempenho discente; a necessidade de diversificação e flexibilização do currículo, tomando por modelo os países com melhor desempenho no Programa Internacional de Avaliação de Alunos (PISA); além de somente 16,5\% dos jovens que ingressam no ensino superior e $8 \%$ que cursam educação profissional, isto é, cerca de $75 \%$ dos jovens tornam-se ocultos para os sistemas educacionais brasileiros e não atingem boa colocação no mercado de trabalho, como justificativa para a introdução do itinerário "formação técnica e profissional".

Além disso, segundo a Organização para a Cooperação e Desenvolvimento Econômico (OCDE), o Brasil ocupa a $60^{\mathrm{a}}$ posição do ranking mundial de educação, também foi visto o desempenho dos estudantes do ensino médio no Sistema da Educação Básica (SAEB) sendo hoje inferior ao resultado de 20 anos atrás e por fim, foi dada atenção as altas taxas de evasão nessa etapa de ensino. Tais argumentos foram fundantes para atestar a necessidade da reforma no ensino médio.

Por outro lado, há teóricos renomados como SAVIANI (2017), que em entrevista concedida ao site Brasil de Fato, questionou o método pelo qual a reforma foi aprovada afirmando que "Essa é uma reforma que, na verdade implica um retrocesso para a década de 1940, quando estava delimitada a formação profissional de um lado e a formação das elites de outro (...)". Posto que, essa reforma não atende as reais necessidades que o sistema educacional brasileiro necessita, pois ela não foi instituída de forma democrática como é divulgada pelos meios midiáticos. 
Diante desse antagonismo de opiniões surgiu o interesse dos membros da nossa equipe da disciplina de Política Educacional em desenvolver o presente artigo, intitulado de Reforma do ensino médio: contexto, caracterização e contrassensos, com o objetivo de refletirmos a respeito das mudanças no ensino médio e suas implicações na realidade educacional dos jovens brasileiros.

\title{
Metodologia
}

O estudo foi construído com base na legislação da reforma do ensino médio, bem como amparado em concepções de autores renomados que tratam sobre a política educacional brasileira. Para tanto realizou-se a pesquisa bibliográfica e documental. Inicialmente, a equipe se apropriou do contexto histórico vigente e suas mútuas relações com o aporte da Lei de $\mathrm{n}^{\circ}$ 13.415 de 2017. Em seguida, a equipe realizou leituras e discussões de artigos, reportagens e textos com visões distintas acerca das mudanças na legislação do ensino secundarista. A partir desses passos o grupo de estudo construiu coletivamente o presente escrito.

\section{Resultados e Discussões}

De acordo com FERREIRA, 2017:

\begin{abstract}
Nos últimos 50 anos, tanto no Brasil como em outros países mais desenvolvidos, a visão sobre a educação assumiu um contorno mais mercantilista, uma presença forte na perspectiva de produção de recursos (conhecimentos e competências) com eficácia e eficiência. Recursos esses tantos úteis para os indivíduos em termos de inserção profissional quanto para toda a sociedade na competição global. (p.298)
\end{abstract}

Este contexto contemporâneo em que se encontra a educação está fortemente ligado a política neoliberal alicerçada no estado mínimo. O ideário neoliberal, através dos organismos internacionais como a Organização das Nações Unidas (ONU), do Fundo das Nações Unidas para Educação, Ciência e Cultura (UNESCO), do Programa das Nações Unidas para o Desenvolvimento (PNUD), do Fundo das Nações Unidas para a Infância (UNICEF) e o Banco Mundial (BIRD) vêm influenciando às reformas educacionais desde a década de 1990, que foi marcada por intensas mudanças e inovações, em vista dos processos de modernização e globalização, provenientes do capitalismo.

Dessa forma, motivados pela tendência econômica neoliberal, governantes e gestores, buscaram a implementação de políticas públicas e investimentos em educação em prol de produzir trabalhadores capacitados ao novo mercado econômico, tendo como decorrência o dualismo na educação, onde a classe mais favorecida economicamente tem o maior acesso ao 
ensino propedêutico, enquanto a classe mais pobre é forçada a ingressar no ensino tecnicista. Em razão dessa nova ordem, o Ministério da Educação Brasileira declinou a reforma do ensino médio numa perspectiva unilateral, sem a participação coletiva e democrática. A reforma focou em quatro áreas principais do sistema educacional, são elas: a carga horária; a formação técnica; o notório saber e as disciplinas obrigatórias.

A carga horária do ensino médio passará de 800 para 1400 horas, onde as escolas devem fazer a ampliação de forma gradual, mas nos primeiros cinco anos devem oferecer 1.000 horas de aula anuais. A $\mathrm{BNCC}^{6}$, que é obrigatória a todas as escolas, deverá ocupar o máximo de $60 \%$ da carga horária total do ensino médio, sendo o tempo restante preenchido por disciplinas de interesse do aluno, que poderá eleger prioridades de acordo com a área de formação desejada em uma das cinco áreas: linguagens, matemática, ciências da natureza, ciências humanas e formação técnica e profissional.

Com a mudança, o jovem optará por uma formação técnica profissional dentro da carga horária do ensino médio regular e, ao final dos três anos, será certificado tanto no ensino médio como no curso técnico. Caberá a cada estado e o Distrito Federal a organização de seus currículos.

Ainda, a reforma prevê a obrigatoriedade das disciplinas de língua portuguesa e de matemática ao longo dos três anos. A língua inglesa passará a ser obrigatória a partir do sexto ano do ensino fundamental. No ensino médio, as redes poderão oferecer outras línguas estrangeiras, prioritariamente o espanhol. Já as disciplinas: filosofia, sociologia, educação física e artes passarão a serem obrigatórias na modalidade de estudos e práticas, mas não necessariamente terão formato de disciplina.

E por fim, no itinerário de formação profissional, poderão ministrar conteúdos os profissionais que apresentarem notório saber reconhecidos pela rede de ensino.

Frente a todas essas mudanças, há dúvidas se o modo como a reforma está sendo instituída nas instituições de ensino público e particular, ocorrerá de forma igualitária, bem como há incertezas sobre a eficácia da reforma já que o investimento é diminuto e esperam resultados volumosos e exitosos. Nesse sentido, precisamos refletir se os estados e o Distrito Federal estão realmente aptos a colocarem em vigor essa nova Lei, visto que não haverá recursos suficientes para implantar as modificações, sobretudo quando se analisa a PEC 241,

\footnotetext{
${ }^{6}$ BASE NACIONAL CURRICULAR COMUM: documento de caráter normativo que define o conjunto orgânico e progressivo de aprendizagens essenciais, que todos os alunos devem desenvolver ao longo das etapas da educação básica.
} 
que instituiu o congelamento por 20 anos dos investimentos dos gastos públicos na área social.

Além disso, a falta de infraestrutura, de planejamento e de superlotação das salas de aula das escolas públicas são fatores que afetam o sistema educacional brasileiro. Diferentemente do que acontece nas escolas particulares em que o número de alunos é reduzido, dispõem de uma melhor infraestrutura no que se refere aos laboratórios e aos recursos didáticos que tornam o ensino mais atrativo e contribuem para um melhor desempenho discente.

Compartilhamos da ideia de que as consequências da referida reforma serão maiores nos sistemas públicos, devido a: 1. Oferta de tempo integral é incompatível com a quantidade de alunos matriculados; 2. Impossibilidade de as escolas ofertarem todas as disciplinas optativas que os estudantes gostariam de cursar, restringindo suas escolhas às opções ofertadas pela instituição; 3. Falta de aporte financeiro, de estrutura física adequada e de recursos humanos para promover a adoção dos itinerários formativos; 4. Indisponibilidade de profissionais da área técnica para atuarem nas escolas públicas por conta da ausência de atrativo financeiro e de condições de trabalho incipientes; 5. Na escola pública o aumento da carga horária poderá acarretar num maior índice de evasão, por motivo do jovem estudante que precisa trabalhar para completar a renda da família.

\section{Conclusões}

Compreendemos que a reforma do ensino médio representou um marco histórico de retrocesso no sistema educacional, uma vez que, por influência da política neoliberal, a nova proposta de educação impõe um ensino preparatório para o mercado de trabalho, que implica na defesa dos interesses das classes dominantes.

É preciso refletir ainda que, a reforma traz uma falsa liberdade de escolha do aluno, haja vista que essa liberdade está intrínseca à oferta da instituição e partindo do pressuposto de que a escola não ofereça o curso desejado será necessário o deslocamento do educando para outra cidade, restringindo o direito assegurado pela Lei. É inquestionável a necessidade de uma reforma não apenas no ensino médio, mas uma reestruturação em todo o sistema educacional.

Além disso, entendemos que será preciso estudos futuros mais aprofundados em relação ao tema abordado neste artigo, dado que ainda não se efetivou a implementação da reforma nas instituições de ensino, tampouco ocorreram efeitos provenientes da mesma.

\section{Referências}


ALESSI, Gil. Entenda o que é a PEC 241 (ou 55) e como ela pode afetar sua vida. EI País. São Paulo, 13 dez. 2016. Disponível em: https://brasil.elpais.com/brasil/2016/10/10/politica/1476125574_221053.html >. Acesso em 26 fev. 2018.

BRASIL. Exposição de Motivos n. ${ }^{\circ}$ 00084/2016/MEC, de 15 de setembro de 2016a. Brasília, 2016a. Disponível em: $\quad$ http://www.planalto.gov.br/ccivil_03/_ato20152018/2016/Exm/Exm-MP746-16.pdf>. Acesso em: 06 mar. 2018.

BRASIL. Ministério da Educação. Base Nacional Comum Curricular. 2017. p. 7. Disponível em: < http://basenacionalcomum.mec.gov.br/wp-content/uploads/2018/02/bncc-20dez-site.pdf $>$. Acesso em: 07 mar. 2018

BRASIL. Observatório do PNE. 2013. Disponível em:

<http://www.observatoriodopne.org.br/metas-pne/17-valorizacao-professor $>$. Acesso em 15 mar. 2018.

FERREIRA, E. B. A contrarreforma do ensino médio no contexto da nova ordem e progresso. Campina, jun. 2017. n. 139. Disponível em:

〈http://www.scielo.br/scielo.php?script=sci_arttext\&pid=S0101-73302017000200293>.

Acesso em 26 fev. 2018.

INEP. PISA - Programa Internacional de Avaliação de Estudantes. 2015. Disponível em: $<$ http://portal.inep.gov.br/pisa $>$. Acesso em 15 mar. 2018.

INEP. Saeb. 2017. Disponível em: < http://portal.inep.gov.br/educacao-basica/saeb >. >. Acesso em: 06 mar. 2018.

LIRA, Davi. Na Finlândia, a profissão de professor é valorizada. Estadão, São Paulo, 27 maio 2013. Entrevista. Disponível em: <http://educacao.estadao.com.br/noticias/geral,nafinlandia-aprofissao-de-professor-e-valorizada-imp-,1035943>. Acesso em 13 mar. 2018

RAMOS, Mauro. PEC do teto dos gastos inviabilizou a educação pública no país, diz Dermeval Saviani. Brasil de Fato, São Paulo, 8 dez. 2017. Educação pública. Disponível em: <https://www.brasildefato.com.br/2017/12/08/pec-do-teto-dos-gastos-inviabilizou-aeducacaopubica-no-brasil-diz-dermeval-saviani/>. Acesso em 10 mar. 2018.

SOUZA, I. Como a reforma do ensino médio vai mudar a educação brasileira? Politize. OUT. 2017. Disponível em 〈http://www.politize.com.br/reforma-ensino-medio/>. Acesso em: 6 mar.2018. 